\title{
"Bloodless" Major Pulmonary Resection in Two Jehovah's Witnesses Patients with Non-Small Cell Lung Carcinoma
}

\author{
Tomer Snir', llya Kirgner ${ }^{2}$, Nachum Nesher ${ }^{3}$, Yaacov Abramov ${ }^{3}$, Marina Kolodii ${ }^{3}$, Sharbel Azzam ${ }^{3}$, \\ Michael Peer ${ }^{3}$ \\ 'Medical Students Elective Program, University of Milan, Milan, Italy; ${ }^{2}$ Blood Bank, Ichilov Medical Center, Tel Aviv, Israel; ${ }^{3}$ Department of Thoracic \\ Surgery, Ichilov Medical Center, Tel Aviv, Israel \\ Correspondence: Michael Peer, Tel +972-3-697202I, Fax+972-3 - 6973235, Email michaelpe@tlvmc.gov.il
}

\begin{abstract}
Background: Blood transfusion rates during surgery and hospitalization for thoracic surgery vary from $16 \%$ to $55 \%$. The religious beliefs of Jehovah's Witnesses (JW) permit medical and surgical procedures but exclude the use of blood and blood products. Performing major pulmonary resection without the possibility of compensating for blood loss is a daunting challenge that few surgeons are willing to meet.
\end{abstract}

Methods: The clinical and surgical data on two JW patients who underwent major pulmonary resections for non-small cell lung carcinoma (NSCLC) in Tel Aviv Medical Center between the years 2019 and 2020 were retrieved from the departmental databases and analyzed for the requirement and consumption of blood products. The patients were a 70-year-old female and a 49-year-old man that have underwent a completion right upper lobe lobectomy and a left lower lobe lobectomy, respectively.

Results: None required blood transfusions and the surgeries were successful, demonstrating that it is possible to successfully perform "bloodless" major pulmonary resection while respecting the limitations set by the patient's religious beliefs.

Conclusion: This concept paves the way for the consideration of major pulmonary resection for patients who are currently denied such procedures due to religious restrictions or to their being high-risk surgical candidates, when resources are limited or lacking.

Keywords: bloodless thoracic surgery, lobectomy, Jehovah's Witnesses

\section{Introduction}

Jehovah's Witnesses (JW) is a Christian denomination whose followers numbered 8.5 million in 2018, and among whom transfusion of allogeneic red blood cells, platelets, and fresh-frozen plasma is forbidden. ${ }^{1}$ Blood transfusion rates during surgery and hospitalization for thoracic surgery vary from $16 \%$ to $55 \% .{ }^{2,3}$ There are only few reports on pulmonary resections for these patients in the literature. ${ }^{4,5}$ We present our experience in carrying out "bloodless" major pulmonary resection on two JW patients, and describe the steps that were taken in order to respect the limitations set by the patients' religious beliefs. These cases provide a unique view into the possibilities that bloodless surgery could benefit not only JW patients, but also members of the general population, such as those at high risk for surgery and living in areas of the world where resources are limited. However, "bloodless" surgery in JW patients continues to carry great risk of morbidity and mortality, ${ }^{6}$ requiring a multidisciplinary team to determine the best approach on a case-by-case basis.

\section{Patients and Methods}

\section{Patients}

The reported patients were referred to the department of thoracic surgery between 2019 and 2020. Each case examined at a tumor board meeting, and surgery was preceded by multidisciplinary discussions that involved surgeons, anesthesiologists, 
the blood bank's medical staff, and hospital administration, together with the patient and family members in the presence of a JW congregation's representative and hospital ethics committee members.

\section{Methods}

Preparation of these surgical patients included special emphasis upon minimizing the need for blood products that would be required for the various types of surgery. The alternative options for blood and blood components consisted of selfdonation, acute normovolemic hemodilution and cell salvage. Intermittent pneumatic compression (IPC) devices used to prevent pulmonary embolism, and hemostatic devices and topical hemostatic sealants, as well as the direct control of bleeding points were applied to reduce blood loss during surgical procedures. The surgeries consisted of a right upper lobe (RUL) completion lobectomy, and a left lower lobe (LLL) lobectomy. The potential operated blood loss was calculated for each patient. A state of controlled hypotension with propofol and remifentanil was used to reduce blood loss, and a normotensive state was ensured prior to completion of the surgery.

\section{Patients Consent for Publication}

The institutional review board approved this study and the patients gave their consent to report the clinical information relating their case for a medical publication.

\section{Case I}

A 70-year-old female (JW member) with a history of hypertension was admitted for a RUL completion lobectomy due to recurrence of a $2.0 \mathrm{~cm}$ primary lung adenocarcinoma according to positron-emission tomography-computed tomography (PET-CT). The preoperative discussion with the patient and family members included explanations on alternative options for blood and blood components. The patient and her family refused self-donation and acute normovolemic hemodilution and agreed only to cell salvage as a last resort in the event of massive bleeding despite having been made aware of a greater risk of hemorrhage due to this being a second thoracic surgery. The coagulation test screen and iron levels were normal, and the hemoglobin level was $13.5 \mathrm{gr} / \mathrm{dl}$. The patient received intravenous folic acid and iron preoperatively for 5 days and $1000 \mathrm{mg}$ tranexamic acid intravenously before the surgery. IPC devices used to prevent a pulmonary embolism. The patient underwent a standard right posterolateral serratus-sparing re-thoracotomy, adhesions between the lung and chest wall scrupulously separated, and an anatomic RUL completion lobectomy performed. Controlled hypotension was maintained with propofol and remifentanil, with return to a normotensive state prior to the completion of surgery. Enhanced hemostasis achieved by a 2.5 cc biological glue EVICEL ${ }^{\text {TM }}$ (Ethicon Inc., Bridgewater, NJ). The operative blood loss was $30 \mathrm{~mL}$. The postoperative period was uneventful, and the patient was discharged on the fifth postoperative day with a hemoglobin level $>13 \mathrm{gr} / \mathrm{dl}$.

\section{Case 2}

A 49-year-old previously healthy male (JW member) was admitted for a LLL lobectomy due to $2.0 \mathrm{~cm}$ primary lung adenocarcinoma according to positron-emission tomography-computed tomography (PET-CT). He refused self-donation and acute normovolemic hemodilution and agreed only to cell salvage. The coagulation test screen and iron levels were normal, and the hemoglobin level was $14.0 \mathrm{gr} / \mathrm{dl}$. The patient received $1000 \mathrm{mg}$ tranexamic acid intravenously before the surgery. IPC devices were used to prevent a pulmonary embolism. A standard posterolateral serratus-sparing thoracotomy incision was made and an anatomic LLL lobectomy performed. Controlled hypotension maintained with propofol and remifentanil, with return to a normotensive state prior to the completion of surgery. The operative blood loss was $10 \mathrm{~mL}$. The postoperative course was uneventful and the patient was discharged on the fourth postoperative day with a hemoglobin level $>13 \mathrm{gr} / \mathrm{dl}$.

Both patients were discharged in good physical condition and are under medical follow-up and disease free to date.

\section{Discussion}

The role of faith in the ability to heal the body both physically and mentally is well recognized. JW patients are known to refuse surgical interventions that involve the administration of blood and/or blood components. Chand et al reported that 
very few of their JW patients (12.5\%) would agree to accept blood transfusion or other blood components. ${ }^{7}$ There are only two publications describing the "bloodless" approach during pulmonary resections. ${ }^{4,5}$ The authors concur with our position that the optimal plan of a "bloodless surgery" must include pre-, intra- and postoperative consideration of strategies that take into account the patient's surgical history, the use of medication potentially causing coagulopathy, and hemoglobin and hematocrit levels, platelet count, and coagulation profile. Minimizing the number of blood samples taken by using lower volume tubes is also important, as well as administration of iron replacement and recombinant human erythropoietin to correct perioperative anemia. On the other hand, "bloodless" surgery in JW patients continues to carry great risk of morbidity and mortality, ${ }^{6}$ despite the thoracic surgeon's efforts to avoid blood loss.

Trzciński et al recently reported that reducing the need for transfusions by ensuring minimal blood loss during surgery is achievable with minimally invasive or staged procedures. ${ }^{8}$ We suppose that the choice of surgical technique should be chosen according to the surgeon's experience in contending with intraoperative hemorrhage. Accordingly, we prefer thoracotomy to thoracoscopy, generally due to better control of hemorrhage, even though thoracoscopy is a less invasive technique. ${ }^{4,5}$

Efforts to reduce operative blood loss improves patient's outcomes. ${ }^{9}$ Shah et al emphasizes different measures employed by surgeons to reduce intraoperative blood loss: stop use of direct acting anticoagulants 48 hours before surgery, intraoperative use of cell salvage when anticipated blood loss is greater than $500 \mathrm{~mL}$, routine administration of tranexamic acid when anticipated blood loss is high, and others. ${ }^{9}$ Direct control of bleeding points and the use of hemostatic devices or topical hemostatic sealants is also useful. The general principles of anesthesia in "bloodless surgery" are starting with continuous hemodynamic monitoring of patient, avoidance of hypothermia during surgery, acute normovolemic hemodilution, regional anesthesia, and the induction of controlled hypotensive anesthesia by maintaining mean arterial pressure of 50-65 $\mathrm{mmHg}$, using a propofol and remifentanil infusion.

We observed that the special measures that we took to respect the JW beliefs did not require extraordinary efforts in executing successful surgeries, but every surgery must be examined on a case-by-case basis. Our experience with these patients leads us to speculate that the general population could also benefit from a "bloodless" surgical environment and thereby possibly extend the surgical conditions under which some high-risk surgical candidates could become suitable for surgery. Other potentially enormous benefits would be the saving of limited resources by meaningful reductions in these requirements, and the possibility of performing the surgeries in the absence of such resources. Another important point contributing to a successful surgery, in our opinion, although not proven scientifically, is the surgeon's ability to identify with and respect the patient's faith. By such consideration, we are able to perform quality surgeries and preserve the patients' rights.

Finally, communication between the surgeons and the anesthesiologists is essential in preparing for major pulmonary resection, and frank communication between the professional team and the patients and their families is the key to the establishment of trust and cooperation when there are obstacles to the unrestricted use of blood products in major thoracic surgery.

\section{Disclosure}

The manuscript is original, there is no conflict of interest in publishing it and no type of grant from any funding agency received. All named authors have given their permission for this submission.

\section{References}

1. Habler O, Voss B. Perioperative management of Jehovah's Witness patients. Special consideration of religiously motivated refusal of allogeneic blood transfusion. Anesthetist. 2010;59:297-311. doi:10.1007/s00101-010-1701-2

2. Gwin JL, Keller SM. Blood transfusion practices after resection of intrathoracic neoplasms. J Surg Oncol. 1993;54:34-37. doi:10.1002/ jso.2930540110

3. Dougenis D, Patrinou V, Filos KS, et al. Blood use in lung resection for carcinoma: perioperative elective anemia does not compromise the early outcome. Eur J Cardiothorac Surg. 2001;20:372-377. doi:10.1016/S1010-7940(01)00792-8

4. Rispoli M, Bergaminelli C, Nespoli MR, et al. Major thoracic surgery in Jehovah's Witness: a multidisciplinary approach case report. Int J Surg Case Rep. 2016;23:116-119. doi:10.1016/j.ijscr.2016.04.024

5. Takagi H, Muto S, Yamaguchi H, et al. Our experience of lung resection in patients who decline blood transfusion for religious reasons. Gen Thorac Cardiovasc Surg. 2021;69:1105-1111. doi:10.1007/s11748-021-01589-2 
6. Shander A, Javidroozi M, Nagvi S, et al. An update on mortality and morbidity in patients with very low postoperative hemoglobin levels who decline blood transfusion. Transfusion. 2014;54:2688-2695. doi:10.1111/trf.12565

7. Chand NK, Subramanya HB, Rao GV. Management of patients who refuse blood transfusion. Indian J Anaesth. 2014;58:658-664. doi:10.4103/ $0019-5049.144680$

8. Trzciński R, Kujawski R, Mik M, et al. Surgery in Jehovah's Witnesses - our experience. Prz Gastroenterol. 2015;10:33-40.

9. Shah A, Palmer AJ, Klein AA. Strategies to minimize intraoperative blood loss during major surgery. Br J Surg. 2020;107b:e26-e38. doi:10.1002/ bjs. 11393

\section{Publish your work in this journal}

The Journal of Blood Medicine is an international, peer-reviewed, open access, online journal publishing laboratory, experimental and clinical aspects of all aspect pertaining to blood based medicine including but not limited to: Transfusion Medicine; Blood collection, Donor issues, Transmittable diseases, and Blood banking logistics; Immunohematology; Artificial and alternative blood based therapeutics; Hematology; Biotechnology/nanotechnology of blood related medicine; Legal aspects of blood medicine; Historical perspectives. The manuscript management system is completely online and includes a very quick and fair peer-review system. Visit http://www.dovepress.com/testimonials.php to read real quotes from published authors.

Submit your manuscript here: http://www.dovepress.com/journal-of-blood-medicine-journal 